\title{
Birth Weight as Destiny: How Parental Investment Reinforces the Birth Weight Educational Gap
}

\author{
Leah Gillion \\ Princeton University
}

\begin{abstract}
Through numerous studies, scholars have come to view birth weight as having a lasting impact on educational outcomes. Normal birth weight is associated with greater educational attainment; however, much of the literature ignores the role of parental investment. Using data from the Fragile Families Child Well-Being Study, it was found that birth endowments alone do not produce varying levels of cognitive development, but these birth endowments do lead parents to make different choices for their children, choices that potentially exacerbate the educational divide. Children with normal birth weight receive more parental investment from birth to age 3 than children with abnormal birth weight. The increased parental investment from birth to age 3 directly increases cognitive scores and the role of parental investment on cognitive scores is amplified indirectly through birth weight. Parents may actually reinforce birth weight differences and, thus, it plays a role in the lingering cognitive gap exhibited later in life.
\end{abstract}

Keywords: birth weight, parenting, child development, parental investment

\section{Introduction}

There is overwhelming support in the literature for the negative effects of low birth weight in the short and long terms (Boardman, Powers, Padilla, \& Hummer, 2002; Case \& Paxson, 2010; Figlio, Guryan, Karbownik, \& Roth, 2014; Jefferis, Power, \& Hertzman, 2002). The consensus is that birth weight is a significant predictor of outcomes in education, employment, and life-long health. Conley and Bennett (2001) found that children with lower birth weights were less likely to graduate on time. A study using Norwegian twin data found that the twin with a higher birth weight was more likely to have a higher IQ, greater educational attainment, and higher wages (Black, Devereux, \& Salvanes, 2005). The existing literature showed the direct effect of birth weight on educational attainment, but these studies failed to account for parenting differences. The question arises: Are parents engaging in different developmental activities with children based on initial health at birth that may reinforce the association between birth weight and cognitive development?

A large body of literature exists on the lingering effects birth weight has on educational attainment and cognitive ability. Many studies examined the gap between children born with low birth weight versus normal birth weight by assessing years of education attained in adulthood or test score differences. Earlier research focused on differences between all low-birth-weight children and normal-birth-weight children and found low-birth-weight children on average have less educational attainment and this holds even while controlling for a number of background measures (Case, Fertig, \& Paxson, 2005; Currie \& Hyson, 1999). Other studies suggest that the negative association between birth weight and educational attainment begins in early childhood (Boardman et al., 2002; Breslau, Johnson, \& Lucia, 2001; Hack, Klein, \& Taylor 1995). Children identified as having low 
birth weight scored significantly lower on reading and math assessment in adolescence (Boardman et al. 2002). These studies could not account for parenting differences and compelling evidence suggest that highly educated parents could partially guard against the negative effects of low birth weight (Currie \& Hyson, 1999). Additionally, low-birth-weight children whose parents graduated high school were more likely to attend college than normal birth weight and low-birth-weight children with less educated parents (Lin, Liu, \& Chou, 2007).

To combat this problem, more recent literature used twin studies to compare children with the same parents, household incomes, and other family characteristics. These studies sought to reduce omitted variable bias due to varying levels of family inputs, but these studies still provided mixed results. A large study among twins in Florida found a positive association between birth weight and state test scores that was established in third grade and was maintained throughout elementary and middle school (Figlio et al., 2014). Further, low-birth-weight siblings were 74\% less likely to graduate from high school by age 19 as compared to a normal birth weight sibling (Conley \& Bennett, 2000). Other studies were not as consistent. A study of Danish twins found significant effects of birth weight on test scores although the magnitude was small (Christensen et al., 2006). In Canada, a study found that gestational weeks had a positive and significant effect on Year 12 school test scores, but when family fixed effects were applied, the relationship disappeared (Oreopoulos, Stabile, Walld, \& Roos, 2008).

Conley and Bennett (2000) theorized that birth weight may be a marker of differential treatment within a family, yet they did not test this theory. The articles mentioned above and other crosssectional studies that rely on fixed effects are limited in that they are unable to account for anything that happens between birth and the measured educational outcome. Sibling and twin fixed-effect models assume that those children received the same upbringing financially and the same parental investment. While many siblings may receive the same financial benefits of living in the same household and neighborhoods, these studies are unable to test if there is variation in parental behavior based on birth endowments. Specifically, do parents respond in a different manner to children who appear to have good health, advanced cognitive abilities, or advanced noncognitive abilities, than those who do not possess these qualities?

A small but growing literature has sought to understand how parents decide to allocate time and resources to children based on countless measurements of birth endowments (Almond \& Mazumder, 2013). Becker and Tomes (1976) theorized that parents make investment decisions based on the "quality" of the child, that is, those with high endowments received more resources in order for families to maximize returns. Some empirical studies found support for the idea that parents invest more resources in children with higher birth endowments (Datar, Kilburn, \& Loughran, 2010; Hsin, 2012); however, these do not indicate if parental investment leads to higher cognitive development. Other studies did not find any differences in parental investment based on birth endowments (Almond \& Currie, 2011). A possible explanation for diverging results can be that they happen due to varying measurement strategies for birth endowments and parental investment, leading to metrics of fundamentally different results.

A long-standing economic view on child development suggested that parents make investment decisions that maximize returns (Becker \& Tomes, 1976). The theoretical model predicted children born with greater endowments receive more parental investment, which accentuates educational outcomes. Numerous studies attempted to test this theory, but the metric used for parental investment varied. Studies used metrics such as parents' educational achievement, doctor well visits, family income, and actual time spent with the child on a weekly basis. The earlier incarnations of the field used the child's educational attainment as a proxy for parental investment and adult IQ, or 
adult earnings as a measurement for birth endowment (Behrman, Rosenzweig, \& Taubman, 1994; Chamberlain \& Griliches, 1977). The problem with using these proxies is that they assume educational attainment is not related to adult IQ or earnings. Furthermore, these proxies for birth endowments are time invariant and measured in adulthood; thus, they are unable to capture how parental investment influences adult IQ.

Other studies captured parental investment by using a variety of metrics while using birth weight as a direct measure of initial endowment, but they found mixed results (Almond \& Currie, 2011; Datar et al., 2010; Hsin, 2012). Almond and Currie (2011) used metrics such as breastfeeding, doctor well visits, caregiver praise, caregiver displays of affection, age of kindergarten entry, food nutrition, and college expectations. They found that parents were more concerned about the low-birth-weight child's school readiness, but, overall, there were no differences in the level of parental investment in children given birth weight endowments. Datar et al. (2010) used similar metrics for parental investment, but focused instead on breastfeeding, doctor visits, immunizations, preschool attendance, and kindergarten entry age. They found parents reinforced birth weight differences and invested less in low-birth-weight babies. This study suggests that parents made different investment decisions that reinforced birth weight differences. Hsin (2012) also found support for different parental investment levels. A notable difference with this study is the use of time diaries from that captured the actual amount of time parents spent with the child on a weekly basis. Differences in parental time investment varied greatly depending on the mother's education level. More educated mothers compensated for low birth endowments while less educated mothers reinforced birth weight differences. Many empirical studies found that parents engaged in different parental investment strategies based on birth weight, but few investigated whether these varying levels of parental investment impact cognitive outcomes. Do parents actually make a difference or does birth weight account for the differences exhibited later in life?

The present study seeks to add to the current literature. As discussed above, prior studies found an association between birth weight and education, but these studies did not investigate if parents are making different decisions for their children. The sibling and twin fixed-effects models attempted to account for parental differences across families, but did not account for differences within families. It is a faulty assumption to assume that parents treat children equally. In fact, there is evidence that parents make different decisions with the amount of time they spend with their children; on average, parents spent less time with low-birth-weight children; however, it is unclear if the additional time spent with the better endowed children is associated with greater cognitive development. The question remains, does greater parental investment in normal-birth-weight children reinforce the cognitive gap exhibited between normal-birth-weight children and abnormal-birth-weight children?

Two core questions were addressed: (1) Do parents make different decisions regarding parental investment based on birth weight? and (2) Do these decisions mediate the effects of birth weight on development? The purpose of this study is to quantify the direct effect of birth weight and the indirect effect of birth weight through parental investment on a child's cognitive development.

\section{Theoretical Framework}

The approach of this study examines how parents mediate the effects of low birth weight. Figure 1 presents a conceptual model of cognitive development. This models shows that birth weight has a direct influence on cognitive development, but parental investment also mediates the effect of birth weight on cognitive ability. More specifically, parental investment reinforces the cognitive gap exhibited in abnormal-birth-weight children. 


\section{Figure 1}

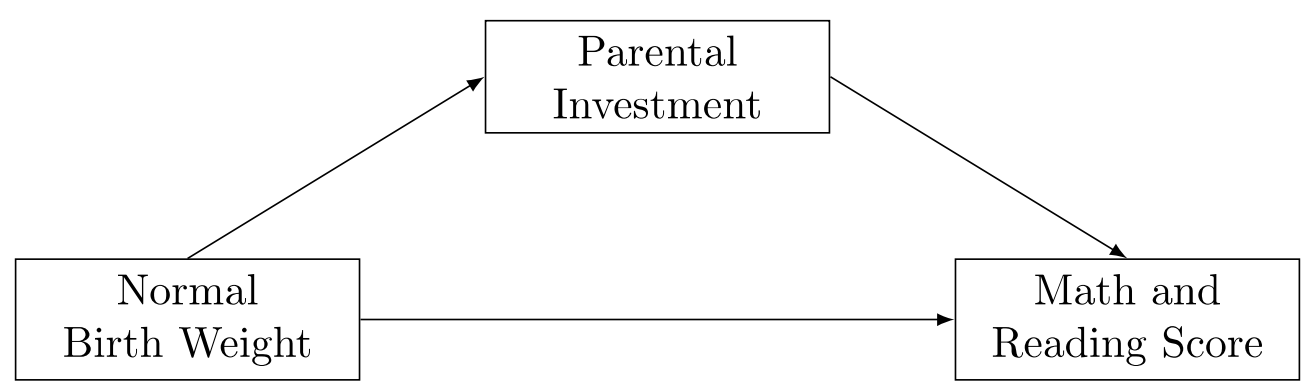

Figure 1. The Pathways Through Which Birth Weight Influences Cognitive Development

Some economic studies suggested that parents made a deliberate decision to maximize returns by investing in the heavier birth weight child. This study theorizes that parents may not make deliberate decisions to maximize returns, but rather it is a function of ease, meaning parents may find it easier to invest time and teach children who have greater birth endowments. Parents have limited time, so spending an hour with the child with greater birth endowments, who on average may have an easier time learning concepts, may be less stressful and more fulfilling than spending an hour with a child with fewer birth endowments, who may have a more difficult time grasping developmental skills. The current study supports prior literature that birth weight is highly predictive of cognitive ability at birth; however, parents' investment decisions widen the cognitive gap exhibited later in life.

Children born with lower birth weights are more likely to have cognition, attention, and gross motor problems (Boulet, Schieve, \& Boyle, 2011; Hack et al., 1995). This may influence how much time a parent invests on their child. Using a cost-benefit analysis Datar et al. (2010) suggested that parents invest human capital into their children at a rate equal to the marginal rate of return of financial assets. In simpler terms, it was theorized that parents may invest more development time with infants who showed greater wage earning potential. This, in turn, may lower parents' educational or developmental expectations for a child, causing parents to make different decisions about a child at an early age.

The theoretical expectations as outlined above led to these specific hypotheses:

Hypothesis 1: It is hypothesized that children born with normal birth weight will have greater parental investment.

Hypothesis 2: It is predicted that the positive association between normal birth weight and cognitive development is mediated by parental investment from birth to 3 years of age. 


\section{Method}

The data from the Fragile Families and Child Wellbeing Study (FFCW) was a longitudinal birthcohort study that followed nearly 5,000 children born between 1998 and 2000 (Reichman, Teitler, Garinfinkel, \& McLanahan, 2001). The sample was collected from 20 large United State cities. Births were randomly selected within hospitals. The data has an over sampling of unmarried families with nearly $75 \%$ of families unmarried at the time of the child's birth. Initial interviews took place within $48 \mathrm{hr}$ after birth and the subsequent interviews took place approximately 1, 3, 5, and 9 years after the child's birth. A drawback of this study was that it did not include families with more than one child. It indicated if the child has a sibling, but did not offer information on multiple children within the same family. The sample analyzed in this study was limited to children without missing data. After restrictions, the final sample was 2,916 children out of the 4,998 possible respondents. A complete description of the data is in the summary statistics in Table 1.

Table1. Summary Statistics

\begin{tabular}{lcc}
\hline & $M$ & $S D$ \\
\hline Dependent variables & & \\
Math score & 98.074 & 16.231 \\
Reading score & 92.813 & 14.073 \\
Combined score & 95.441 & 13.779 \\
Independent variable & & \\
Child characteristics & & \\
$\quad$ Birth weight (g) & $3,229.253$ & 606.721 \\
$\quad$ Rate of low birth weight & 0.101 & 0.301 \\
$\quad$ Rate of normal birth weight & 0.825 & 0.380 \\
$\quad$ Gender (1 = male) & 0.520 & 0.500 \\
$\quad$ Eldest child & 0.387 & 0.487 \\
Child race & & \\
$\quad$ Black & 0.557 & 0.497 \\
$\quad$ Hispanic & 0.201 & 0.401 \\
$\quad$ White & 0.168 & 0.374 \\
$\quad$ Other & 0.074 & 0.262 \\
Maternal and family characteristics & & \\
Parental investment & 102.697 & 15.668 \\
Family income & $35,670.440$ & 1.543 \\
Log family income & 9.868 & 1.011 \\
Mother's education & 1.222 & 5.976 \\
Mother's age at child's birth & 24.997 & 0.464 \\
Marital status (1 = married) & 0.313 & \\
\hline
\end{tabular}

Despite some data limitations, the FFCW data is well suited for this study because it contained measures of parental investment, birth endowments, and included cognitive assessments. A normal birth weight indicator variable was used to measure a normal-birth-weight child, which takes a value of 1 if the child weighs between 2,500 $\mathrm{g}$ and 4,000 $\mathrm{g}$ at birth and zero otherwise. As in the literature, normal birth weight is a useful endowment measure since it has been shown to have important and long-lasting effects on a variety of child outcomes and is often used as a proxy for birth endowments (Almond \& Currie, 2011).

The Woodcock-Johnson Standardized (WJS) scores in reading and math are assessed in Year 9. This is a widely used test to assess cognitive abilities that was developed in 1977 . The FFCW used the 
2001 version. The WJS has a scoring range of 0 to 200 with a mean of 100 and a standard deviation of 15 points. In general, students who score between 90 and 110 are considered average and $50 \%$ of the population scores within this range. Students who scored between 80 and 89 are considered to have low-average ability, students who scored between 70 and 79 are classified as low ability, and those who scored below 70 are classified as very low ability.

The parental investment variable was derived from the number of activities the mother reported performing with the child on a weekly basis from birth to age 3 . This age range was chosen, primarily because investment in children at a young age has the largest impact (Case et al., 2005). The activities changed year-to-year to capture age-appropriate activities, and asked how often parents participated in these activities on a weekly basis. In Year 1, activities included singing songs, reading stories, playing peekaboo, or showing affection. In Year 3, many of the activities overlapped, but they also included playing imaginary games with the child and having the child help with simple chores. An index was created by summing the total number of days per week a parent engaged in these activities with the child in Years 1 and 3. This created a parental investment index ranging from 0 to 126 .

Figure 2 is a descriptive figure that illustrates the activities parents spent with their children on a weekly basis based on birth weight. In this data set, parents spent the most time with normal-birthweight children, but they invested the least amount of time with high birth weight children. Parents also spent slightly less time with moderately low and very low-birth-weight children than normalbirth-weight children.

\section{Alternative Explanations}

This study controlled for a number of individual and family characteristics. Four different racial and ethnic groups constituted the sample. They were non-Hispanic White, non-Hispanic Black, Hispanic, and biracial non-Black (includes White-Hispanic, White-other, and other). Non-Hispanic White was the reference category. Due to data limitations, there was not a large enough sample to include other racial and ethnic categories. The study controlled for gender, because boys typically develop at a slower rate than girls during elementary years. Prior literature showed the eldest children typically spent more time with parents, to make sure this was not the case, the study accounted for birth order.

Many family-level variables were also included, such as household income, parents' marital status, and various characteristics of the biological mother. A measure of whether the biological mother and father were married by Year 3. The study also controlled for the mother's education, which was a discrete variable from 0 to 3: less than high school (0), high school/GED (1), some college (2), or college degree (3). Lastly, the mother's age at child's birth was taken into account. 


\section{Parent Activities Per Week by Child's Birth Weight Status}

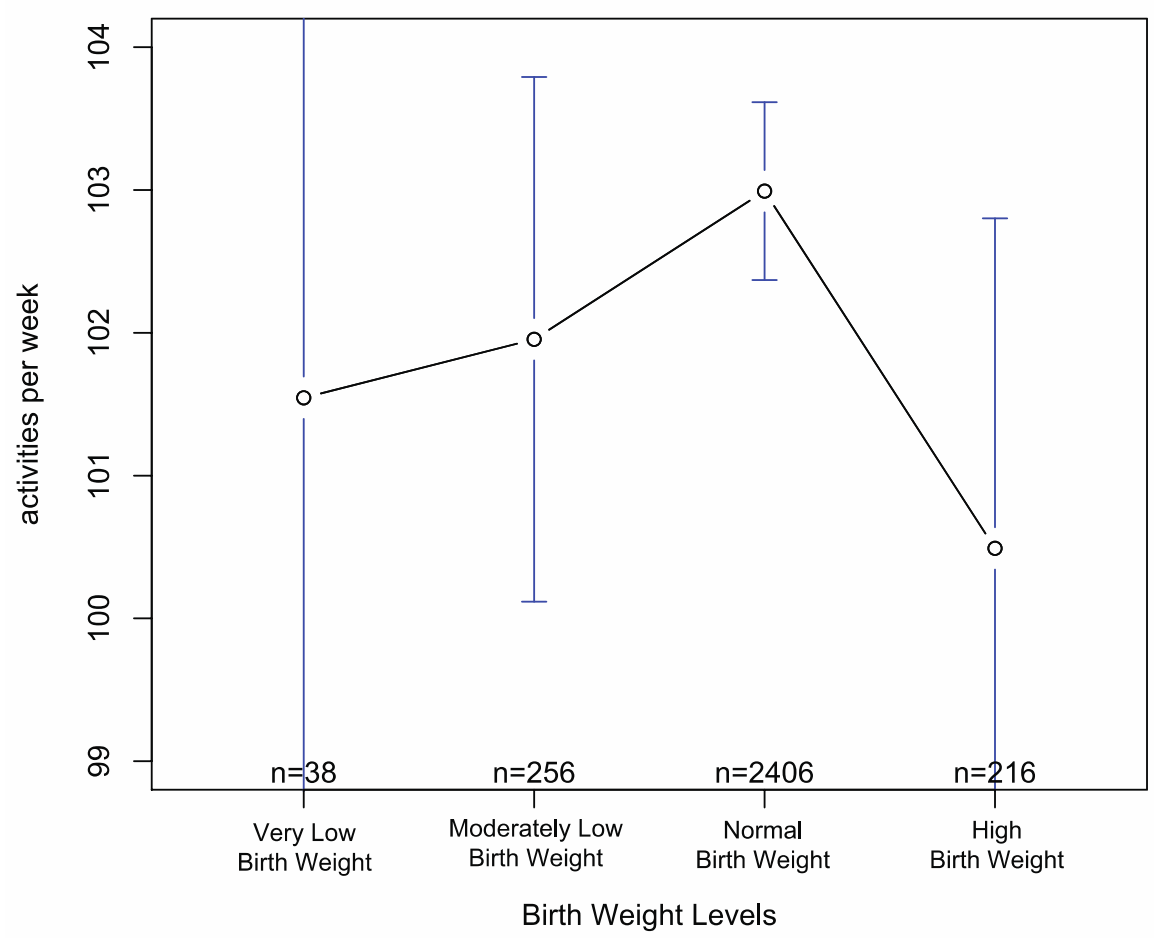

Figure 2. The Average Weekly Activities a Parent Partook in With Their Child Dependent on Birthweight

\section{Analyses}

A causal mediation analysis was used to address the stated hypotheses (Imai, Keele, \& Tingley, 2010). This is a good fit for the analysis carried out in this study, as the model seeks to identify causal mechanisms that explain the relationship between the independent and dependent variable. Relating the model to this analysis, it was hypothesized that birth weight (independent variable) directly affects cognitive development (dependent variable); however, there is the third mediating variable, which is parental investment that indirectly influences cognitive development through birth weight (see Figure 1). To estimate the indirect mediating variable of parental investment, the follow empirical strategy was used:

$$
\begin{aligned}
& Y_{i}=\alpha_{1}+\beta_{1} N B W_{i}+\mu_{1}^{n} X_{i}+\varepsilon_{i 1}, \\
& M_{i}=\alpha_{2}+\beta_{2} N B W_{i}+\mu_{1}^{n} X_{i}+\varepsilon_{i 2}, \text { and } \\
& Y_{i}=\alpha_{3}+\beta_{3} N B W_{i}+\gamma M_{i}+\mu_{1}^{n} X_{i}+\varepsilon_{i 3},
\end{aligned}
$$


where $Y_{i}$ is each individual, $i$ 's, WJS scores; $N B W_{i}$ is a dichotomized variable where 1 is normal birth weight and 0 is abnormal birth weight for each individual, $i ; X_{i}$ are the control variables for each individual $i$; and $\varepsilon_{i}$ is the error term for each equation. This first step of the analysis found the effect of the normal birth weight on cognitive development. Equation 2 found the impact of the birth weight on the mediator, $M_{i}$, where $M_{i}$ is parental investment. The third and final equations regressed parental investment on the WJS scores, while controlling for birth weight and a host of control variables. Finally, a quasi-Bayesian Monte Carlo approximation, using 1,000 simulations was run to provide point estimates and confidence intervals that assess the significance of the direct effect from birth weight and the indirect effect of birth weight through parental investment on cognitive scores.

Mediation analysis allowed for a better understanding of the mechanism through which the independent variable influenced outcomes. This method, determined how much of a direct effect birth weight had on WJS scores and how much of an indirect effect birth weight had on cognitive development through parental investment (Imai et al., 2010).

\section{Results}

The results to test Hypothesis 1 -that parents invested more time with normal-birth-weight children-are displayed on Table 2. This hypothesis was based on the idea that parents spent more time with children who have normal birth weights, because they may find these activities easier to complete with greater endowed children. Columns 1 and 2 used the full sample, Columns 3 and 4 analyzed first-born children, and the final two columns examined noneldest children or those who had an older sibling. The data was split into eldest children and noneldest children to ensure this was not a story of the oldest child simply having more individual time with parents.

Table 2 confirmed the hypothesis that parents made greater investments in normal-birth-weight children than abnormal-birth-weight children. This hypothesis held in the full sample, eldest child, and even in the younger sibling sample. Although, there were slight variations in the number of activities a parent invested in the eldest child versus a younger sibling, there is a clear distinction between the amount of time invested in a normal-birth-weight child and a abnormal-birth-weight child.

Parents spent more time with normal-birth-weight children, even while controlling for a number of individual and family characteristics. The full model using the full sample in Column 2 showed parents, on average, participated in 1.84 more activities per week with a normal-birth-weight child. The controls also displayed large variations between minorities and Whites in parental investment levels. Black mothers, on average, participated in five fewer activities per week than White mothers, while Hispanics engaged in seven fewer activities per week than Whites. As expected, education, income, and being the eldest were positively associated with higher levels of parental investment. These findings were consistent with the literature that parents spent more time with better birthendowed children and also first-born children have more time with parents than nonfirst-born children (Datar et al., 2010; Hsin, 2012). The interpretation of these findings is that parents do make time-investment decisions concerning children based on birth endowments. 
Table 2. Regression Results of Normal Birth Weight on Parental Investment Birth to Age 3

\begin{tabular}{|c|c|c|c|c|c|c|}
\hline & \multicolumn{6}{|c|}{ Dependent Variable: Parental Investment (0-3) } \\
\hline & \multicolumn{2}{|c|}{ Full Sample } & \multicolumn{2}{|c|}{ Eldest Child } & \multicolumn{2}{|c|}{ Noneldest Child } \\
\hline & (1) & (2) & (3) & (4) & (5) & (6) \\
\hline Normal birth & $1.688 * * *$ & $1.840 * *$ & 1.373 & 2.235 & $1.665^{*}$ & $1.661^{*}$ \\
\hline & $(0.763)$ & $(0.743)$ & $(1.186)$ & $(1.138)$ & $(0.984)$ & $(0.975)$ \\
\hline Marital status & & $\begin{array}{l}-0.034 \\
(0.710)\end{array}$ & & $\begin{array}{l}-0.398 \\
(1.091)\end{array}$ & & $\begin{array}{c}0.192 \\
(0.933)\end{array}$ \\
\hline Mother's education & & $\begin{array}{l}1.742^{* * *} \\
(0.342)\end{array}$ & & $\begin{array}{l}1.866^{* * *} \\
(0.516)\end{array}$ & & $\begin{array}{l}1.713^{* * *} \\
(0.457)\end{array}$ \\
\hline Log income & & $\begin{array}{l}0.445^{* *} \\
(0.207)\end{array}$ & & $\begin{array}{l}0.640 * * \\
(0.284)\end{array}$ & & $\begin{array}{c}0.296 \\
(0.291)\end{array}$ \\
\hline $\begin{array}{l}\text { Mother's age at } \\
\text { birth }\end{array}$ & & $-1.198^{* *}$ & & -0.093 & & $-0.193 * * *$ \\
\hline Gender $($ male $=1)$ & & $\begin{array}{c}(0.563) \\
-1.198 \\
(0.563)\end{array}$ & & $\begin{array}{c}(0.098) \\
-1.271 \\
(0.836)\end{array}$ & & $\begin{array}{c}(0.070) \\
-1.113 \\
(0.752)\end{array}$ \\
\hline $\begin{array}{l}\text { Race and ethnicity } \\
\text { (ref. category: White }\end{array}$ & & & & & & \\
\hline Black & & $\begin{array}{c}-5.022^{* * *} \\
(0.867)\end{array}$ & & $\begin{array}{c}-7.507 * * * \\
(1.204)\end{array}$ & & $\begin{array}{c}-2.972^{* *} \\
(1.220)\end{array}$ \\
\hline Hispanic & & $\begin{array}{c}-7.370 * * * \\
(0.996)\end{array}$ & & $\begin{array}{c}-10.046^{* * *} \\
(1.377)\end{array}$ & & $\begin{array}{c}-5.129^{* * *} \\
(1.404)\end{array}$ \\
\hline Mixed & & $\begin{array}{l}-2.274 \\
(1.244)\end{array}$ & & $\begin{array}{c}-3.379 * * \\
(1.626)\end{array}$ & & $\begin{array}{c}1.513 \\
(1.842)\end{array}$ \\
\hline Eldest child & & $\begin{array}{c}2.359 * * * \\
(0.634)\end{array}$ & & & & \\
\hline Constant & $\begin{array}{c}101.304^{* * *} \\
(0.693)\end{array}$ & $\begin{array}{c}102.715^{* * *} \\
(2.650)\end{array}$ & $\begin{array}{c}103.881^{* * *} \\
(1.086)\end{array}$ & $\begin{array}{c}103.245^{* * *} \\
(3.724)\end{array}$ & $\begin{array}{c}99.862^{* * *} \\
(0.889)\end{array}$ & $\begin{array}{c}103.511^{* * *} \\
(3.579)\end{array}$ \\
\hline Observations & 2,916 & 2,916 & 1,129 & 1,129 & 1,787 & 1,787 \\
\hline$r^{2}$ & 0.002 & 0.065 & 0.001 & 0.105 & 0.002 & 0.031 \\
\hline Adjusted $r^{2}$ & 0.001 & 0.062 & 0.0003 & 0.098 & 0.001 & 0.026 \\
\hline$d f$ & 2,914 & 2,905 & 1,127 & 1,119 & 1,785 & 1,777 \\
\hline Residual $S E$ & 15.658 & 15.175 & 14.690 & 13.954 & 16.076 & 15.871 \\
\hline$F$ statistic & $4.890 * *$ & $20.256^{* * *}$ & 1.339 & $14.614^{* * *}$ & $2.865^{*}$ & $6.391 * * *$ \\
\hline
\end{tabular}

Columns 3 through 6 analyzed Hypothesis 1, but distinguished between first-born and nonfirst-born children to ensure that birth endowments were associated with parental investment regardless of birth order. These results provided a similar result as in the full sample, where parents spent more time on average with the normal-birth-weight child; however, it was found that parents reinforced birth weight differences even more for the first-born child. When children are the eldest and of normal birth weight, parents invested 2.24 more activities per week than with eldest children who have abnormal birth weights. Even when children are not the oldest, parents still invest more time with normal-birth-weight children and invest 1.66 more activities per week then younger sibling abnormal-birth-weight children. 
The second part of the mediation analysis provided regression results for effect of normal birth weight on WJS reading, math, and combined scores. Consistent with prior literature, there was a positive relationship between normal birth weight and cognitive scores in reading and math. This means better endowed children at birth score higher on assessments at age 9 .

The final regression analysis examined the effect of parental investment on the WJS math and reading scores in Year 9, while controlling for birth weight. It showed that normal birth weight and higher parental investment were associated with higher scores. In additional analysis, the eldest child benefited more from parental investments. Each additional activity for the eldest child resulted in a 0.17-point increase on the WJS combined score, while younger siblings only received a 0.06-point increase on the WJS assessment for each additional parental activity. Because the results from the effect of birth weight on reading scores and math scores yielded similar results, for subsequent analysis, the combined WJS scores were used to assess outcomes.

The study addressed Hypothesis 2-that the direct effect birth weight had on cognitive development was mediated through parental investment-in Table 3, using a mediation analysis. Table 3 showed the average causal mediated effect and the average direct effect for the full sample as well as eldest children and younger siblings. The causal mediation analysis showed there was a direct effect of birth weight, on WJS. On average, children with higher birth weight received higher test scores than abnormal-birth-weight children in all three samples. The mediation analysis yields the indirect effect of the birth weight though parental investment. The mediator parental investment also had a positive and significant effect on test scores. The full sample showed that a 1-unit increase in parental investment increased WJS by 0.065 points in children with normal birth weight. Parents invested up to 126 developmental activities per week with their child from the survey. Using linear assumptions, this model suggested that parents who made the greatest investments from birth to age 3 could increase children's test scores by over 8 points.

Table 3. Causal Mediation Analysis

\begin{tabular}{lccc}
\hline & $\begin{array}{c}\text { Estimate } \\
(1)\end{array}$ & $\begin{array}{c}95 \% \text { CI Lower } \\
(2)\end{array}$ & $\begin{array}{c}95 \% \text { CI Upper } \\
(3)\end{array}$ \\
\hline Full sample & & & \\
$(N=2,916)$ & & & \\
$\quad$ ACME & $0.0648^{* *}$ & 0.0060 & 0.1586 \\
ADE & $1.9190^{* * *}$ & 0.7933 & 3.0343 \\
$\quad$ Total effect & $1.9838^{* * *}$ & 0.8337 & 3.0944 \\
Eldest child sample & & & \\
$(n=1,129)$ & & & \\
$\quad$ ACME & $0.1349^{*}$ & 0.0097 & 0.3318 \\
ADE & $2.2368^{* *}$ & 0.4661 & 4.3228 \\
$\quad$ Total effect & $2.4917^{* *}$ & 0.5636 & 4.4923 \\
Noneldest child sample & & & \\
$(n=1,787)$ & & & \\
$\quad$ ACME & 0.0352 & -0.0316 & 0.1360 \\
ADE & $1.6567^{* *}$ & 0.1070 & 3.1928 \\
$\quad$ Total effect & $1.6919^{* *}$ & 0.1452 & 3.2199 \\
\hline
\end{tabular}

Note. CI = confidence interval (quasi-Bayesian); ACME = average causal mediation effect; ADE = average direct effect. Simulations $=1,000$. 
Interestingly, the results showed that children who were not the oldest did not benefit from parental investment in the same manner as the eldest child. Younger siblings with normal birth weight only scored 0.035 points higher on the WJS per parental activity, while the eldest child who had normal birth weight, benefited greatly from increased parental investment and realized a 0.135 increase in WJS.

Figure 3 synthesized the results from the full sample. Birth weight increased parental investment and higher levels of parental investment increased cognitive scores. Normal birth weight had a direct and positive association on WJS scores. It also had an indirect effect that was mediated through parental investment. The mediation model demonstrated that parental investment mediated the effect of birth weight and actually reinforced birth weight differences. Parents invested more time with the normal-birth-weight child by investing 1.84 more activities per week. Parental investment also had a direct effect on cognitive scores with an increase of 0.035 per additional activity for all children regardless of birth endowments. The normal-birth-weight children had a direct benefit of 0.035 per activity of parental investment and a 0.065 indirect effect per activity, which results in a 0.10 per activity total impact of parental investment. Thus, not only did parents spend more time with normal-birth-weight children, but also the additional investment translated into higher cognitive scores. Parents effectively were contributing to the educational birth weight divide.

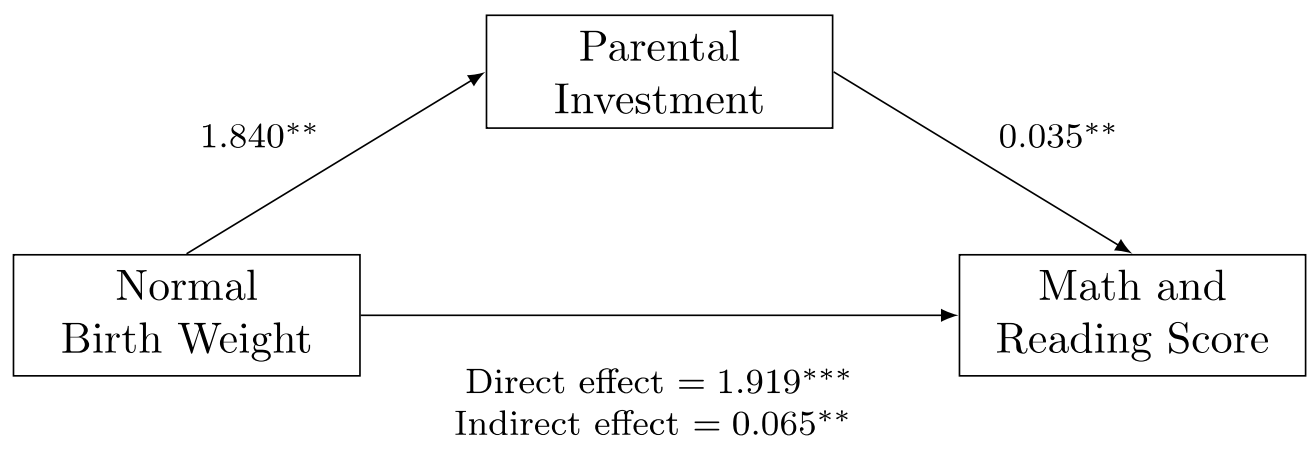

Figure 3. The Path Analysis of the Direct Effect of Birth Weight on Year 9 Math and Reading Scores and the Pathway Through Which Normal Birth Weight Was Mediated Through Parental Investment (Indirect Effect) to Affect Year 9 Scores

\section{Discussion}

This study found that parental investment mediated the relationship between birth weight and cognitive ability. This means that the cognitive gap exhibited between normal-birth-weight children and abnormal-birth-weight children can be partially explained by different levels of parental investment. Essentially, parents' behavior reinforced birth weight differences.

The current study makes several contributions to the literature. First, parents spent more time with normal-birth-weight children. They invested an additional two activities per week; this is consistent with prior literature that parents made different investment decisions based on birth endowments (Almond \& Mazumder, 2013). This is not simply the result of eldest child having more parental investment opportunities, since birth order was taken into account. The results show that parents spent more time on average with children who had normal birth weight regardless of birth order. 
Also consistent with prior literature, more educated mothers invested more time in their children. This study revealed a strong association between birth weight and parental investment and adds to the literature on this growing topic.

Second, the study found a positive relationship between parental investment and cognitive ability. Prior studies that investigated the relationship between birth weight and parental investment failed to establish this relationship (Almond \& Currie, 2011; Datar et al., 2010; Hsin, 2012). Even though the magnitude of the effect is small, the idea that parents can hinder or help children's cognitive ability is a relief. Most of the work on birth weight and cognitive ability believes that "birth weight is a destiny" and there is not much to alter this outlook (Black et al., 2005; Conley \& Bennett, 2000; Figlio et al., 2014).

Third, mediation analysis revealed that not only do normal-birth-weight children receive more parental investment, but normal-birth-weight children benefited more from the additional parental investment. More specifically, the additional time spent with the normal-birth-weight child increased cognitive score by 0.10 points per activity, while parents who invest an additional activity per week with abnormal-birth-weight children only increase the cognitive scores by 0.035 points. Thus, 126 activities with a normal-birth-weight child yielded a total increase of 12.6 points on the WJS assessment and an abnormal-birth-weight child will only realize a 4.41 point increase.

A gain of 4.41 points on the WJS assessment is nearly one third (0.294) of a standard deviation unit. The difference gained from parental investment between normal-birth-weight children in abnormalbirth-weight children is roughly 8 points, which is slight higher than half (0.546) of a standard deviation difference. This assessment already takes race, family income, and mother's education into account. To understand the context of these results, it is helpful to understand the impact of other factors from prior studies. A controversial book cited that the Black-White cognitive gap is $1 S D$ (Herrnstein \& Murray, 1994). Other studies found that stereotype threat accounted for as much as $0.75 S D$ between Blacks and Whites (Steele \& Aronson, 1995). Additionally, poverty is found to account for a 13-point difference between those in poverty and not in poverty (Tucker-Drob \& Bates, 2015). These factors are more difficult for parents to control, while parenting style can more easily be adapted. Thus, simply participating in more developmental activities on a weekly basis from birth to age 3 increased low-birth-weight children's cognitive development by $0.294 S D$ is significant in comparison to other inputs.

Parental investment is an important tool, but as a caution, these results compare parents who invest zero activities to those who invest the full amount of activities. This is unrealistic, because all parents in the study invest some amount of activities in their child. Instead, these results highlight the importance of parents spending time with their children at an early age, because there are tangible benefits. This is especially helpful for children with abnormal birth weight. Yet, parents invest less time in abnormal-birth-weight children than normal-birth-weight children. Additionally, abnormal-birth-weight children lower cognitive returns from each parental activity than normalbirth-weight children. Closer attention should be paid to the amount of time parents invest in abnormal-birth-weight children to help close the cognitive gap exhibited later in life.

This study has some limitations, especially due to the scope and precision of the data. First, in comparison with prior studies, this study does not have data on children within the same family. Thus comments could not be made on if mothers with normal and abnormal-birth-weight children made different investment decisions among their children. This study is only able to make comparisons across families. Secondly, there are large discrepancies in the amount of time invested between Black mothers, White mothers, and Hispanic mothers, which were not explained by family 
status, education, or family income. This may be due to the construction of the survey; the parental activities survey may have a cultural bias that favored White mothers. Also this study focused on children living in large cities and there is a large oversampling of Black children. This may limit generalizability, especially to children living in rural areas. Finally, there is an oversampling of Blacks and Hispanics and there is not enough data outside of Blacks, Whites, and Hispanics to gain any meaningful insight. Despite these limitations, the results presented here are robust. The analysis concerning the effect of birth weight on cognitive scores and the effect of birth weight on parental investment were consistent with prior literature.

Previous studies established that birth weight was an important predictor of cognitive ability, but few studies investigated mediating factors could alter the cognitive gap between. Normal birth weight appears to be important not only to cognitive development, but also to predict parents' willingness to invest time in their child. This study found that parental involvement can minimize some of the risk associated with lower birth weight. This study showed that parents have the power to improve cognitive development through developmental activities at a young age. These findings can have policy implication on how the federal government directs its resources to reduce inequality. The government could promote social change through federal programs or incentives. There may be a lack of knowledge as to how to care for children with abnormal birth weights and the government could incentivize or mandate hospitals to discuss with expectant mothers ways to promote child development. Therefore, positive social change can be made simply through exposure to the information on how to care for a child with abnormal birth weight. Policy has the potential to play a central role in reducing the cognitive gap due to birth weight differences.

\section{References}

Almond, D., \& Currie, J. (2011). Killing me softly: The fetal origins hypothesis. The Journal of Economic Perspectives, 25, 153-172.

Almond, D., \& Mazumder, B. (2013). Fetal origins and parental responses. Annual Economics Review, 5, 37-56.

Becker, G., \& Tomes, N. (1976). Child endowments and the quantity and quality of children. Journal of Political Economy, 84, 143-162.

Behrman, J. R., Rosenzweig, M. R., \& Taubman, P. (1994). Endowments and the allocation of schooling in the family and in the marriage market: the twins experiment. Journal of Political Economy, 102, 1131-1174.

Black, S. E., Devereux, P. J., \& Salvanes, K. (2005). From the cradle to the labor market? The effect of birth weight on adult outcomes. The Quarterly Journal of Economics, 122, 409-439.

Boardman, J. D., Powers, D. A., Padilla, Y. C., \& Hummer, R. A. (2002). Low birth weight, social factors, and developmental outcomes among children in the United States. Demography, 39, 353-368.

Boulet, S. L., Schieve, L. A., \& Boyle, C. A. (2011). Birth weight and health and developmental outcomes in U.S. children, 1997-2005. Maternal and Child Health Journal, 15, 836-844.

Breslau, N., Johnson, E. O., \& Lucia, V. C. (2001). Academic achievement of low birthweight children at age 11: The role of cognitive abilities at school entry. Journal of Abnormal Child Psychology, 29, 273-279.

Case, A., Fertig, A., \& Paxson, C. (2005). The lasting impact of childhood health and circumstance. Journal of Health Economics, 24, 365-389. 
Case, A., \& Paxson, C. (2010). Causes and consequences of early-life health. Demography, 47, 65-85.

Chamberlain, G., \& Griliches, Z. (1977). More on brothers. In P. Taubman (Eds.), Kinometrics: Determinants of socioeconomic success within and between families (pp. 97-124). New York, NY: North-Holland Publishing Co.

Christensen, K., Petersen, I., Skytthe, A., Herskind, A. M., McGue, M., \& Bingley, P. (2006). Comparison of academic performance of twins and singletons in adolescence: Follow-up study. BJM, 333, 1095.

Conley, D., \& Bennett, N. G. (2000). Is biology destiny? Birth weight and life chances. American Sociological Review, 65, 458-467.

Conley, D., \& Bennett, N. G. (2001). Birth weight and income: interactions across generations. Journal of Health and Social Behavior, 42, 450-465.

Currie, J., \& Hyson, R. (1999). Is the impact of health shocks cushioned by socioeconomic status? The case of low birthweight. The American Economic Review, 89, 245-250.

Datar, A., Kilburn, M. R., \& Loughran, D. S. (2010). Endowments and parental investments in infancy and early childhood. Demography, 47, 145-162.

Figlio, D., Guryan, J., Karbownik, K., \& Roth, J. (2014). The effects of poor neonatal health on children's cognitive development. The American Economic Review, 104, 3921-3955.

Hack, M., Klein, N. K., \& Taylor, H. G. (1995). Long-term developmental outcomes of low birth weight infants. The Future of Children, 5, 176-196.

Herrnstein, R. J., \& Murray, C. (1994). Bell curve: Intelligence and class structure in American life. New York, NY: Free Press.

Hsin, A. (2012). Is biology destiny? Birth weight and differential parental treatment. Demography, $49,1385-1405$.

Imai, K., Keele, L., \& Tingley, D. (2010). A general approach to causal mediation analysis. Psychological Methods, 15, 309-334.

Jefferis, B. J., Power, C., \& Hertzman, C. (2002). Birth weight, childhood socioeconomic environment, and cognitive development in the 1958 British birth cohort study. BMJ, 325, 305-308.

Lin, M. J., Liu, J. T., \& Chou, S. Y. (2007). As low birth weight babies grow, can well-educated parents buffer this adverse factor? A research note. Demography, 44, 335-343.

Oreopoulos, P., Stabile, M., Walld, R., \& Roos, L. L. (2008). Short-, medium-, and long-term consequences of poor infant health an analysis using siblings and twins. Journal of Human Resources, 43, 88-138.

Reichman, N. E., Teitler, J. O., Garinfinkel, I., \& McLanahan, S. S. (2001). Fragile families: Sample and design. Children and Youth Services Review, 23, 303-326.

Steele, C. M., \& Aronson, J. (1995). Stereotype threat and the intellectual test performance of African Americans. Journal of Personality and Social Psychology, 69, 797.

Tucker-Drob, E. M., \& Bates, T. C. (2016). Large cross-national differences in gene $\times$ socioeconomic status interaction on intelligence. Psychological Science, 27, 138-149.

(Appendices follow) 


\section{Appendix A}

\section{Classification of Standard Scores of the Woodcock-Johnson Assessment}

\begin{tabular}{ll}
\hline Standard Score Range & Woodcock-Johnson Classification \\
\hline 131 and above & Very superior \\
121 to 130 & Superior \\
111 to 120 & High average \\
90 to 110 & Average \\
80 to 89 & Low average \\
70 to 79 & Low \\
69 and below & Very low \\
\hline
\end{tabular}




\section{Appendix B}

\section{Year 1 and Year 3 Activities}

\section{Year 1 Activities}

1. Days/week mom plays games like peek-a-boo or gotcha with child

2. Days/week mom plays games like peek-a-boo or gotcha with child

3. Days/week mom reads stories to child

4. Days/week mom tells stories to child

5. Days/week mom plays inside with toys such as blocks or Legos with child

6. Days/week mom hugs or shows physical affection to child

7. Days/week mom puts child to bed

8. How many times since birth has child been to health care professional for well visit?

\section{Year 3 Activities}

1. Days/week mom sings songs or nursery rhymes with child

2. Days/week mom hugs or show physical affection to child

3. Days/week mom tells child that you love him/her

4. Days/week mom lets child help you with simple chores

5. Days/week mom plays imaginary games with him/her

6. Days/week mom reads stories to child

7. Days/week mom tells stories to child

8. Days/week mom plays inside with toys with child

9. Days/week mom tells child you appreciate something he/she did

10. Days/week mom puts child to bed

The Journal of Social, Behavioral, and Health Sciences is an open-access, peer-reviewed, online interdisciplinary journal focusing on research findings that address contemporary national and international issues. Its objectives are to (a) encourage dialogue between scholars and practitioners in the social, behavioral, and health sciences that fosters the integration of research with practice; (b) promote innovative models of interdisciplinary collaboration among the social, behavioral, and health sciences that address complex social problems; and (c) inform the relationship between practice and research in the social, behavioral, and health sciences.

Walden University Publishing: http://www.publishing.waldenu.edu 